\title{
Moderating Effects of Transforming High-Potential Local Employees for Reverse Adaptation, through the Lens of Absorptive Capacity: The Case of Hi Tech in Egypt
}

\author{
Said Shabban Abdo ${ }^{1}$, David Edgar ${ }^{2} \&$ Gamal Kamel $^{3}$ \\ ${ }^{1}$ Marketing department, Modern University for Technology \& Information, Cairo, Egypt \\ 2 Department of Business Management at Glasgow Caledonian University, UK \\ ${ }^{3}$ Department of Accounting, Nahda University, Beni Suef, Egypt \\ Correspondence: Said Shabban Abdo, Marketing department, Modern University for Technology \& Information, \\ Cairo, Egypt. E-mail: said.shabban@nub.edu.eg
}

Received: April 10, 2020

Accepted: April 30, 2020

Online Published: May 21, 2020

doi:10.5539/ijbm.v15n6p171

URL: https://doi.org/10.5539/ijbm.v15n6p171

\begin{abstract}
The purpose of this research is to provide new insights into the moderating effects that enable an MNE operating in Egypt to learn to attract, motivate, transform and develop its high-potential local employees for reverse adaptation so as to fit a global mind-set elsewhere in the organisation's global positions. The methodology uses semi-structured story-based interviews to explore the significance of moderating effects and practices of absorptive capacity and reverse adaptation in Hi Tech in Egypt. The findings reveal the interrelated components that lead to reverse adaptation and how continuous management development is intermediated by learning and well-bonded reciprocity of relationships, amid continuous management development, transformation, and reverse adaptation. This virtuous cycle acts as an integrated adaptation learning loop that supports the process of transformation. The findings refute the linearity of the absorptive capacity model as the transformation stage does not appear to mediate the model but precedes other steps within it. Moreover, it was concluded that the model did not end in achieving the competitive advantage phase. Instead reverse adaptation, as a by-product, acted as a trigger for knowledge acquisition. The originality here is based on a greater understanding of the moderating effects that mediate the relationship between reverse adaptation and the transformation stage of absorptive capacity theory. This allows awareness of how, in the case of the Hi Tech in Egypt, the global mindset is delivered and offers valuable contributions to theory and practice. As reverse adaptation is a nascent multidisciplinary phenomenon for research, the paper also suggests a research agenda for researchers in the area of international management.
\end{abstract}

Keywords: reverse adaptation, absorptive capacity, transformation, Hi Tech, Egypt

\section{Introduction}

To be globally competitive in a landscape with an increasing number of expatriate employees, particularly managers (Causin \& Ayoun, 2011), Multinational Enterprises' (MNEs) need to recruit managers who can manage culturally and geographically dissimilar groups and interact with business associates and other stakeholders in foreign contexts (Bird \& Mendenhall, 2015). To overcome the scarcity of capable talent, particularly to fill leadership roles (Lim, Dai \& Meuse, 2009), MNEs have the option of either recruiting externally or sourcing local talent (Caligiuri, 2006) and investing in "developing (such) employees with the ability to adapt to various situations and fit into global roles" (Schmidt et al., 2014, p.2). This has inspired MNEs to form talent management schemes to develop and cultivate their own future managers (Collings \& Mellahi, 2009). In this respect, successful expatriates in overseas roles are recognised as having cross-cultural intelligence (Zhang, 2012) exemplified by well-developed relationship skills, integrity, curiosity, maturity, cognitive flexibility and networking skills (Santoso \& Loosemore, 2013). Other key characteristics are identified as strategic awareness, adaptability, sensitivity, financial knowledge and marketing experience (Cousin \& Ayoun, 2013).

However, employing expatriates with such profiles incurs greater costs, including higher salaries and "additional compensation [ie] housing, private drivers, medical cover, travel, schooling for children, and security" (Pegram 
et al., 2018, p. 7). Thus, the "challenge for multinational organizations is to attract, develop, and retain local talent with a global mind-set" in preference to more costly expatriates (Meyer \& Xin, 201 8: p.2). This strategy of replacing expatriates by skilled host country nationals, termed localization, is highly evident in many Middle Eastern countries. Such localization is "a process in which local officers increase their competencies and consequently improve their performance. The main objective is to train and develop locals to enable them to replace expatriates with competency and efficiency" (Bhanugopan \& Fish, 2007, p. 366). However this process can be problematic as the underlying cultural norms may "not be compatible with industry needs" (Pegram et al., 2018, p. 8).

Consequently, it has been recognized that it is advantageous to devote resources to developing local talented people with the skills to adapt to a range of varying circumstances and fit into international roles (Schmidt et al., 2014). To do this, some MNEs try to balance 'Western' workforces with local talent to apply relevant performance assessments and ensure fair chances for promotion (Meyer \& Xin, 2018).

According to Schmidt et al.'s (2014), while MNEs in China are experiencing a scarcity of global leaders; they do not encounter any substantial difficulties in implementing and executing their global approach. They offer two plausible explanations for this: "Western MNEs are attracting and recruiting Chinese talent with a Western mind-set, and Chinese nationals are adapting to the Western concept of leadership, not the other way around." (Schmidt et al., 2014, p. 108). This approach is termed reverse adaptation, which is where an MNE's local employees learn, assimilate and modify their personal behaviour (e.g. values, norms) and professional competence (e.g. standards, goals, language, knowledge, capabilities) to fit the MNE's global mind-set and global competence (Luo, 2016, p. 29). Reverse adaptation is, therefore, a way of preparing local talent for international reassignment (Liu et al., 2018, p.15). Thus, investigating how MNEs develop and cultivate their local talent, and the way these individuals learn to fit the MNE's global mind-set and global competence, offers the opportunity to develop and extend mainstream theories and literature (Luo, 2016, p. 39). Along these lines, Studies by Yao and Chang (2017) and Latukha (2018) found that talent development can be linked with a firm's absorptive capacity, and the extent to which it is fostered. Our research uses absorptive capacity as a theoretical lens to investigate ways in which a MNE's local employees learn, assimilate and modify their personal behaviour and professional in order to fit the MNE's global mind-set and global competences. We use a large progressive MNE high technology company operating in Egypt as our case. To keep the company anonymised we call it " $H i$ Tech".

\subsection{Absorptive Capacity as a Concept}

Absorptive capacity refers to the presence of routine organizational practices that permit organizations to continuously modify, integrate, build, and reconfigure their internal and external capabilities to cope effectively with rapidly changing environments (Wang \& Ahmed, 2007). This is based on "the ability to recognize the value of new information, assimilate it and apply it to commercial ends" (Cohen \& Levinthal, 1990, p. 128).

Zahra and George (2002) suggest two categories of absorptive capacity that create value: the first is potential absorptive capacity (PACAP), which comprises processes of acquisition and assimilation of knowledge, while the second is realized absorptive capacity (RACAP). This latter comprises transformation and exploitation, i.e. developing and refining "routines that allow the firm to refine, extend and leverage existing competencies or to create new ones by incorporating acquired and transformed knowledge into its operations" (Zahra \& George, 2002, p.190).

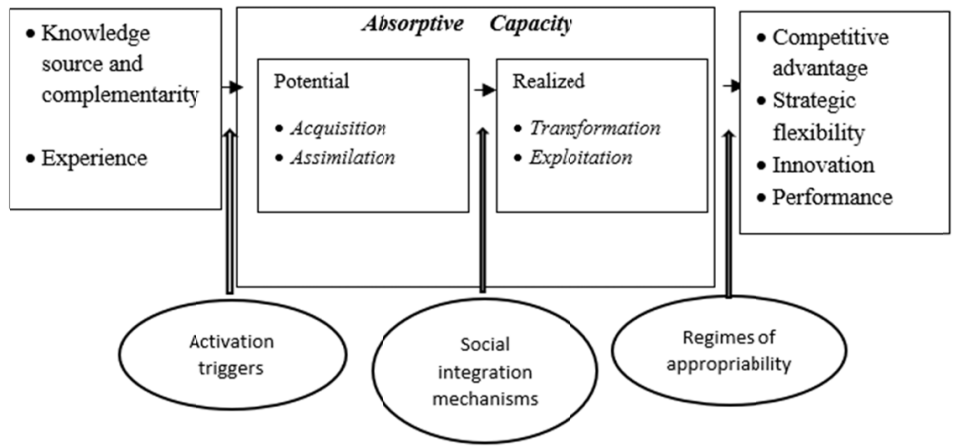

Figure 1. Model of Absorptive capacity 
Source: Zahra and George (2002, p. 192).

As the moderators of Figure 1, the activation triggers mediate the influence of knowledge sources and practice in the development of absorptive capacity. These triggers are "events that lead the firm to respond to specific stimuli such as internal organizational crises, or external stimuli such as radical innovations, technological changes or regulatory changes" (Engelman \& Schreiber, 2018, p. 7).

Social integration mechanisms are characterized by a cluster of administrators aiding in sharing useful knowledge, either exchanging ideas informally, through social networks, or in a more formal and systematic way (Zahra \& George, 2002, p. 194). The third moderating factor is referred to as regimes of appropriability, which relates to "the industrial and institutional dynamics that affect the firm's ability to create not only advantages and benefits out of new products or processes, but also isolating mechanisms to protect knowledge" (Engelman \& Schreiber, 2018, p. 8).

Thus the aim of this research is to obtain a better understanding of how individual local talent learn to adapt their organizational strategies, culture and structure (Reverse Adaptation) so that they can be globally reassigned. This understanding is acquired by focusing on the dimensions of absorptive capacity as a ground and theoretical lens of continual learning in organizations.

\subsection{The role of Human Resource Development in Supporting Talent Development}

By ascribing the right people to the right places in an organization, and developing dynamic capabilities, human resources development (HRD) closely contributes to the learning and development of local talent for assuming international positions. Thus, this study investigated the role of human resource development as a part of developing local talent in a Hi Tech MNE organization operating in Egypt.

\subsection{Human Resource Development and Absorptive Capacity for Cultivating Local Talent}

It has been argued that effective development of talented employees is the base of effective assimilation and exploitation of knowledge through various activities of talent recruitment, performance management, employee training and development, and communication (Aljanabi \& Kumar, 2013) This process accentuates the interplay between human resource development and absorptive capacity in fostering talent in local employees. Thus, there has been a call for research aimed at elucidating the relationship between talent development and learning as a process of the absorptive capacity phases (Latukha, 2018).

\subsection{Research Questions}

The aim of this research is to investigate, through the lens of the phases of the absorptive capacity theory (Zahra $\&$ George, 2002), the role of human resource development in fostering the absorptive capacity of Hi Tech's local employees. Through this approach they are encouraged to learn, assimilate and modify their personal behaviour (based on values and norms) and professional competence (standards, goals, language, knowledge, capabilities) in order to fit $\mathrm{Hi}$ Tech's global mind-set and global competence set so that they can be internationally reassigned.

To meet the above overarching aim, the questions to be answered are:

1. What kinds of talent development strategies are used in Hi Tech MNEs? Can these be related to learning which affects the absorptive capacity (employee's ability to acquire, assimilate, transform, and exploit knowledge) in Hi Tech?

2. How do talent localization and cultural integration practices work in Hi Tech?

3. What are the main challenges in working with expatriates from various countries and host country nationals, and how has Hi Tech overcome these challenges?

4. How and why does $\mathrm{Hi}$ Tech assist its local employees to learn in order to be prepared to manage in other $\mathrm{Hi}$ Tech international subsidiaries?

5. How are the selection, training, development and retention processes in Hi Tech conducted?

\section{Method}

\subsection{Research Method and Design}

A qualitative approach was used to explore how Hi Tech's local employees learn, assimilate and modify their personal behaviour (e.g. values, norms) and professional competence (e.g. standards, goals, language, knowledge, capabilities) in order to fit the MNE's global mind-set and global competence set so that they can be internationally reassigned. 


\subsection{Participants}

Table 1. Interviews with senior managers in Hi Tech Egypt

\begin{tabular}{|c|c|c|c|c|c|c|c|c|}
\hline No. & Name & Gender & Nationality & Job Title & Industry & Location & Profile & $\begin{array}{l}\text { Addition- } \\
\text { al Skills }\end{array}$ \\
\hline 1 & $A Z$ & Male & Egyptian & $\begin{array}{l}\text { Senior } \\
\text { Manager }\end{array}$ & $\begin{array}{l}\text { Information } \\
\text { technology }\end{array}$ & $\begin{array}{l}\text { Cairo/ } \\
\text { North } \\
\text { Africa } \\
\text { Region }\end{array}$ & $\begin{array}{l}12 \text { years of } \\
\text { experience in } \\
\text { Information } \\
\text { technology }\end{array}$ & $\begin{array}{l}\text { English } \\
\text { Chinese } \\
\text { Dutch } \\
\text { Soft/hard } \\
\text { skills } \\
\text { trainer }\end{array}$ \\
\hline 2 & AS & Male & Egyptian & $\begin{array}{l}\text { Senior } \\
\text { Manager }\end{array}$ & $\begin{array}{l}\text { Information } \\
\text { technology }\end{array}$ & $\begin{array}{l}\text { Cairo/ } \\
\text { North } \\
\text { Africa } \\
\text { Region }\end{array}$ & $\begin{array}{l}10 \text { years of } \\
\text { experience in } \\
\text { Information } \\
\text { technology }\end{array}$ & $\begin{array}{l}\text { English } \\
\text { Arabic } \\
\text { Chinese }\end{array}$ \\
\hline 3 & $A Y$ & Male & Egyptian & $\begin{array}{l}\text { Senior } \\
\text { Manager }\end{array}$ & $\begin{array}{l}\text { Information } \\
\text { technology }\end{array}$ & $\begin{array}{l}\text { Cairo/ } \\
\text { North } \\
\text { Africa } \\
\text { Region }\end{array}$ & $\begin{array}{l}12 \text { years of } \\
\text { experience in } \\
\text { Information } \\
\text { technology }\end{array}$ & $\begin{array}{l}\text { English } \\
\text { Chinese }\end{array}$ \\
\hline 4 & MG & Male & Egyptian & $\begin{array}{l}\text { Senior } \\
\text { Manager }\end{array}$ & $\begin{array}{l}\text { Information } \\
\text { technology }\end{array}$ & $\begin{array}{l}\text { Cairo/ } \\
\text { North } \\
\text { Africa } \\
\text { Region }\end{array}$ & $\begin{array}{l}12 \text { years of } \\
\text { experience in } \\
\text { Information } \\
\text { technology }\end{array}$ & $\begin{array}{l}\text { English } \\
\text { Chinese } \\
\text { Soft skills } \\
\text { trainer }\end{array}$ \\
\hline 5 & WE & Male & Egyptian & $\begin{array}{l}\text { Senior } \\
\text { Manager }\end{array}$ & $\begin{array}{l}\text { Higher } \\
\text { Education }\end{array}$ & $\begin{array}{l}\text { Cairo/ } \\
\text { North } \\
\text { Africa } \\
\text { Region }\end{array}$ & $\begin{array}{l}28 \text { years of } \\
\text { experience in } \\
\text { Higher } \\
\text { Education }\end{array}$ & $\begin{array}{l}\text { English } \\
\text { Chinese } \\
\text { Soft skills } \\
\text { trainer }\end{array}$ \\
\hline
\end{tabular}

Following the recommendation that the sample size for an interview in phenomenological research study should be not less than three to five participants with experience of the phenomenon (Englander, 2012), the sample size for this research was five senior managers with experience in training and development of international cross-cultural teams. The selected participants all had rich experiences of managing individuals from different ethnicities and backgrounds in $\mathrm{Hi}$ Tech Egypt, as shown in Table 1. A code was allocated to each interviewee in place of their names, and they received a consent form, assuring them that their confidentiality would be maintained.

\subsection{Data Collection Instruments}

Semi-structured interviews were used for data collection. The interview process was open-ended and consisted of asking five questions aimed to obtain real life stories about the respondents' experiences and perceptions. The interviews were conducted face-to-face in the offices at Hi Tech Egypt. The duration of the interviews was between 40 and 52 minutes.

\subsection{Data Analysis}

Thematic analysis was considered appropriate for the purpose and nature of this research (Braun \& Clarke, 2006), following data analysis procedures laid out by Creswell and Poth (2018). Coding and analysis were carried out manually.

\subsection{The Conceptual Framework}

According to Albort-Morant et al. (2018, p. 3) the most relevant stage is the Transformation Stage, accomplished by adding or deleting knowledge, or by simply interpreting knowledge in a different way. This stage, "re-conceptualization of absorptive capacity", appears to be "the most widely used, conceptualized, operationalized, and measured, and also seems most representative of the models present in the literature" (Ali et al., 2018. p. 109). Moreover, absorptive capacity relates to the employee's behaviour (Hart et al., 2016). In line with these considerations, almost all the studies have investigated the multidimensional connotations of absorptive capacity as an incorporated concept of all four dimensions. Thus they have approached it as a linear process, without examining which stage is dominant, on the grounds that, "if all the other phases do not lead to knowledge exploitation, they will not have been proven to be very useful" (Albort-Morant et al., 2018, p. 4). This view has been encouraged by Zahra and George's (2002) four-phase ACAP (absorptive capacity) model. However, no studies in the current literature have investigated whether there are other moderators mediating these four phases. Indeed, this model has been characterised as a "black box" (Aribi \& Dupouet, 2016, p. 87). Thus, the current research will adopt Zahra and George's (2002) definition of absorptive capacity as a conceptual framework to address the research questions. In line with the above argument, a conceptual framework is proposed, specifically, human resource strategies and activities in fostering the four phases of ACAP for developing the learning capacity of locals to adopt their organization's strategy, culture and structure so as to be prepared for being reassigned globally. The framework examines the direct effects of human resources development strategy and absorptive capacity on developing the capability of local talent, through the lens of the ACAP framework. This is following Latukha (2018), who underscores the transformation stage as the dominant 
phase and as a by-product of HRD activities undertaken in cultivating and developing talented locals to prepare them to be globally re-employed.

\section{Findings and Discussion}

\subsection{Analysing Findings through Zahra and George's (2002) ACAP model in Hi Tech Egypt}

To conduct the analysis, the data was prearranged according to the groups and themes in the absorptive capacity model, namely, sources of knowledge and complementary knowledge, experience, activation triggers, social integration mechanisms, sustaining competitive advantage and the property rules of the ownership regime, strategic flexibility, innovations, and performance. The findings revealed that the ACAP model is not limited to the last three outcomes, nor does it start with acquisition of knowledge, as stated by Zahra and George's (2002) model. Rather, the current research empirically demonstrated that there are some phases which precede knowledge acquisition as the first stage in the model. Moreover, it was found that some moderators have to be incorporated in the model to enable the global reassignment of Hi Tech, employees, as explained in the following sections.

\subsubsection{Organizational, Team, and Individual Previous Experience as Enablers of Learning in Hi Tech Egypt}

According to Levitt and March (1988) knowledge is managed in the organization by individuals, grounded on the learning and experience of other employees within the same organization. These individuals offer varied contributions to the assimilation processes and transformation of new knowledge based upon their own extensive experience (Sjodin \& Frishammar, 2015), This reservoir of assimilated knowledge intensifies the absorptive capacity of the firm, particularly in knowledge-intensive firms where knowledge inflow is very fast (Minbaeva et al., 2014). The experiences in Zahra and George's (2002) ACAP model have to do with "past success, environment examination, learning by doing" (Engelman \& Schreiber, 2018, p. 7).

"I have twelve years of work experience in the enterprise Dept. I used to work in Orange and Al Masrea for telecommunications. 'Hi Tech', has long-lasting experience and knowledge, and considered as one of the major players in the field of technology and telecommunication in the world..." (AZ).

"I have ten years of working experience, I'm working in the telecommunication equipment, we have patents to provide the major players in that field in Egypt, ... so we are working in a very competitive environment against our competitors like Alcatel, Eriksson, and Nokia," (AS).

"I'm working as a senior manager since 2007, in 'Hi Tech' Egypt. 'Hi Tech' is the market leader in Egypt with $70 \%$ of the Market share in Egypt, and 50\% of the global market" (AY).

"We provide on-job training, and orientation paid period so as to encourage and attract talent individuals with different expertise to apply and join our company" (WE).

The above quotes indicate that the three levels of experience, gained by the organization, team, and individual, can influence $\mathrm{Hi}$ Tech's performance through the transfer of knowledge that leads to the learning of individuals in the organization.

The findings of this research corroborate other academic findings that organizational experience is "the cumulative production history of the organization" (Reagans, Argote, \& Brooks, 2005 p. 870), which aids the prospect of learning as a firm and is acquired by individuals. Team experience is the "cumulative production history of pairs of individuals" (Reagans et al., 2005, p. 870), which can support learning by increasing team members' awareness of experienced and knowledgeable individuals and by creating trust and suitable leadership styles between individuals. Individual experience is defined as "cumulative production history of any one individual" (Reagans et al., 2005, p. 870), which provides the opportunity for them to become more skilled in their organization from learning-by-doing, from disasters or through absorptive capacity. Moreover, learning from diverse levels of experience has a substantial impact on performance. Indeed, "Heterogeneous experience has been found to increase learning outcomes more than homogeneous experience" (Argote \& Miron-Spektor, 2011, p. 1127). To underpin the acquisition of knowledge as the first phase of absorptive capacity requires workforces to have varied experience (Zahra \& George, 2002). These endeavours have to be from a wide range of company, affiliate, and individual levels (Luo, 2016). Thus, as prior knowledge and experience do not arise spontaneously (Todorova \& Durisin, 2007), it is contingent on individuals to acquire external environment expertise (Cohen \& Levinthal, 1990, p. 132).

Thus, organizational, team, and individual previous experience are all deemed as enablers of learning. Through learning by doing, employees in $H i$ Tech Egypt are enabled to harness their absorptive capacity, which may, in turn, help them to be globally reassigned. 


\subsubsection{Learning through Strategic Alliances for Talent Development in Hi Tech Egypt}

Absorptive capacity has been defined as the ability to create, sustain and gain value from external knowledge: "it is the firm's capacity to learn and resolve difficulties" (Albort-Morant et al., 2018, p. 3). External knowledge can be generated by strategic alliances, through which organizations share their knowledge and create innovative thinking to escalate performance and create value (Hansen, 2002).

The participants confirmed that they were looking out of their company's borders to search for and delve into knowledge from external resources, so as to share knowledge and create innovative ideas. Absorptive capacity is the main factor for gaining increased competitiveness from external knowledge, since it facilitates organisational learning by assisting organizations to assess, understand, assimilate, and incorporate such knowledge with the firm's internal knowledge repository. This then allows the organization to implement this knowledge in its product innovation (Lane \& Lubatkin, 1998).

"In 'Hi Tech', Egypt we have three business groups, with roughly 3000 employees; the first is responsible for the mobile services and its companies ... the second business group related to tablets, devices, and digital components; the third group related to the enterprises, establishments, and organizations ... of which we gain, acquire, transfer, and utilise knowledge mutually"(AZ).

"We have patents to provide the major players in the telecommunications field in Egypt ... so we are working in a very competitive environment against our competitors" (AS).

"We are selling also educational solution programs for university, including staff, employees, students, competitors, and suppliers" (MG).

From the excerpts above, it can be seen that $H i$ Tech's employees utilise the reciprocity of knowledge just knowledge passing between suppliers, organizations and universities to create, refine and define new routines and processes to deal with this new knowledge. In turn, they learn new ways and process by transforming their mind-set and way of thinking to achieve competitive advantage. This confirms, alongside other academic contributions, that this external knowledge can be obtained from "Inter-organizational relations (formal or informal with other companies, or institutions in search of diverse and complementary knowledge), and the greater the firm's exposure to external sources of diverse and complementary knowledge, the greater the opportunity for the firm to develop its PACAP" (Engelman \& Schreiber, 2018, p. 8).

Thus, knowledge-intensive organizations like Hi Tech Egypt rely on external knowledge. Employees need to accentuate this stage of the knowledge process, with focused efforts to generate new routines and practices for handing on this new external knowledge. This process requires the transformation of each employee's mind-set and talent development in the organization. Thus, rather than mediating the ACAP model, as claimed by Zahra and George (2002), it appears that the transformation stage needs to precede the identification and acquisition of knowledge.

\subsubsection{Learning by Developing Capabilities for Satisfying Triggers for Reverse Adaptation}

Zahra and George (2002, p. 193) posit that there are particular triggers - "events that encourage or compel a firm to respond to specific internal or external stimuli." Such events activate absorptive capacity by controlling the influence that knowledge sources and experience have on acquisition, assimilation, transformation, and exploitation of knowledge.

"Thus, according to the need of each group, we do our meetings to discuss these needs, update our employees with the required technology" (AZ).

"Business need is our main reasons for calling for a full week meeting, so as to find solutions to our customers in how external technologies will be marketed, fit our customer's expectations, and needs, produced and dominated in the market against over our competitors. In these meetings ... we can communicate and share our knowledge with each other," (AS).

"Big part of our products are dealing with certain generation, such as millennials, who are technologically fans with different needs and wants from their earlier generations, and also we are looking forward to dealing with generation $Z$ also, with different demands from millennials, thus, we learn how to act quickly to satisfy these different demands in different cultures" (MG).

In the above extracts, the senior managers confirm that they regard satisfying the market and customers' needs as a way of learning. This may take the form of calling meetings with their senior peers and executives so as to find technological solutions to satisfy the different triggers of the market. In addition, they also stated that, through this process, they learn how to respond nimbly to different triggers in different cultures. This way of learning 
will definitely necessitate different competencies, skills, attitude and values, and even developing new mind-sets. The findings concur with those of Jones (2006) regarding the significance of the organization's prior experience as an internal trigger for the absorption of external knowledge and competencies in finding solutions for practices and products.

Thus, triggers could be the questions firms address to look for knowledge and, therefore, "Reasons for seeking new knowledge" (Engelman \& Schreiber, 2018, p. 8). These questions precondition new skills, attitudes and competencies, so that they can be suggested in different contexts. This confirms Zahra and George's (2002) view that the intensity of these triggers will affect an organization's investment in increasing the competences needed to acquire and assimilate the new knowledge, so as to promote learning through satisfying these triggers. It appears that the mind-set of senior managers of Hi Tech Egypt has to be first transformed and appropriately prepared with competencies, values and skills before responding to organizational triggers for different contexts and generations. Thus, the employee's transformation phase appears not to mediate the process of the ACAP model; rather it precedes the four stages of the ACAP model identified by Zahra and George (2002). It then has to be fostered and nurtured to transform the employee's competencies, attitudes, and skills, to fit them to be globally reassigned.

\subsubsection{Transformation of Local Potential through Knowledge Acquisition for Reverse Adaptation}

Acquisition is defined as the phase in which an organization can critically acquire external knowledge (Cohen \& Levinthal, 1990). Lane, Salk and Lyles (2001) suggest that acquiring knowledge from a cooperative partner could be deemed as a sign of absorptive capacity, at the acquisition phase. Particularly, R\&D collaboration benefits organizations by allowing them to obtain new knowledge (Zahra \& George, 2002; Jansen et al., 2005). According to Gold et al., (2001, p. 190) the terms associated with the acquisition phase, such as searching, generating creating, seeking and collaboration, "all have one theme in common: the accumulation of knowledge". Acquisition competence emphasises the organization's ability to localise and acquire external knowledge critical for its activity (Flatten et al., 2011). Thus, in this study, cooperation and R\&D collaboration are used as an indication of knowledge acquisition.

"We have bi-weekly meetings with our employees to update them with our research findings and the most recent outcomes of research which come from our R\&D centres in China, available exclusively for our staff. In 2017-18 ... we spent and fund roughly \$14 million just on scientific research and innovations purposes." (AZ).

“We get our new ideas, innovations, and updated information from our HQs' experts and our R\&Ds from China, and Egypt, this information transferred to us through extensive seminars, workshops, executives and their subordinates on how we can operationalise their provided information into products ...." (AY).

"We sent our local high potential employees to get privileged of the knowledge and outcomes of these researches, our strategies and systems of HQs, both theoretically and practically, so as to benefit their colleagues, transfer this knowledge through experience, and get global experience and knowledge so as to fit for any of our positions globally." (WE).

Thus, these senior managers confirmed that they acquired and captured potential knowledge through cooperation with their HQs, by transferring the research findings and outcomes of their research at R\&D centres all over the world to disseminate the unique knowledge that helped them in innovations. The benefit of this approach has been confirmed in previous studies (Zahra \& George, 2002 and Jansen et al., 2005).

Likewise, the participants stated that this information accumulated in repositories can be acquired and captured through their endeavours to develop potential employees in Hi Tech Egypt. This is achieved by sending them to China for training, as well as through meetings, social events or seminars to acquire the transferred knowledge from their partners in the HQs and their R\&D centres, to promote innovation. These reported activities corroborated the findings of other academic studies regarding the activities associated with knowledge acquisition. In this way, "training programs become the main source of new knowledge, where the acquisition process can be associated with the socialization and externalization modes of knowledge conversion" (Latukha, 2018, p. 448).

In addition, the senior managers confirmed that they acquire their innovative ideas and inventions from representatives from their headquarters in China, India and Egypt. They also send their potential employees to those locations to benefit from $\mathrm{Hi}$ Tech's strategy, structure and policy and, in turn, transfer this acquired knowledge, together with innovations, and technological information, to their colleagues elsewhere. These practices were triggers for reverse adaptation, as it is argued that innovation is primarily proven in poorer (emerging) economies and then replicated elsewhere, in developed countries (Govindarajan \& Ramamurti, 2011). 
Moreover, the reason why reverse adaptation is needed today is that "many MNEs learn to generate successful innovations in emerging markets and then export that knowledge and those innovations to many other countries" (Luo, 2016, p. 32). This calls for transformation of potential employees to be able to reassign them elsewhere in Hi Tech's subsidiaries all over the world, as explained in these extracts. This concurs with the views of Luo (2016) that: "transforming local talent so that they become global talent becomes an essential component of global knowledge flow within an MNE, and is a key task in the augmentation and fulfilment of reverse innovation" (p. 32). Thus, it appears that reverse adaptation is both a complementary stage and a by-product of the ACAP model, as it constitutes a trigger for knowledge acquisition in the case of Hi Tech Egypt.

\subsubsection{Learning How to Develop Potential Employees through Assimilation}

Assimilation can be defined as the "capability to analyse, interpret and understand external knowledge obtained through organizational routines and processes" (Zahra \& George, 2002, p. 189). This means that new understandings and thinking are suitable to be transferred to the existing repository of knowledge (Todorova \& Durisin, 2007). It is also consistent with Kim's (1997) conclusion that investing in R\&D would benefit organizations and entice external experts who participate to compress the absorption cycle of externally acquired knowledge. R\&D has been accentuated as crucial for organizational progression (Jansen et al., 2005). According to Kumar (1995), one of the three drivers for international organizations to execute R\&D activities in a foreign country is to absorb the overflow of foreign R\&D activity. Therefore, to absorb this overflow, "Hi Tech" decided to build its R\&D centres in developed countries, where they are close to well-known international institutions of higher learning or industry leaders" (Lin et al., 2018, p. 83). These authors recently drew attention to the link that interconnected R\&D, the absorption of knowledge, and obtaining talented and high potential leaders. This is because ACAP "is perceived as the outcome of an investment in research and development" (Ali et al., 2018, p. 108). Consequently, learning can be developed by fostering the ACAP of high-potential locals through investment in $\mathrm{R} \& \mathrm{D}$, which will be considered as the main indicator to determine the assimilation phase in $H i$ Tech Egypt.

"We develop our staff via what we call it "war room", where we allow our potential employees to deal with the unknown problems that might occur, arming them with different solutions for new situations, and how to assimilate what they have acquired of knowledge from either our suppliers, R\&D centres, HQs ( headquarters) and even from our counterparts. We are working in an incessant learning chain, from everywhere you get and share the information." (AS).

"Innovative ideas come from our centre of $R \& D$ in China and transferred via formal and informal meetings ... to update our potential employees with most relevant information, to our current knowledge, allowing us to also discuss ... its applicability in the Egyptian context." (AY).

“'Hi Tech'spent between 30 to $40 \%$ of its revenues on the R\&D ... in our research centres all over the world, so as to get the most recent and valuable knowledge in the world via our experts' visits our potential returnees from the HQs, videoconferences, links, and web-interface." (WE).

As illustrated in the above excerpts, Hi Tech has spent a huge amount of money on its R\&D and created activities to develop its staff by allowing them to interpret and understand the external knowledge acquired and assess its applicability in different situations. They also stress the role of their executives at Hi Tech Egypt in assimilating knowledge from their R\&D centres, HQs, and partners in China and elsewhere. They then share this knowledge with their colleagues from Egypt and China to reduce communication gaps.

They even assimilate knowledge from their competitors to enable staff to solve the problems they encounter. This highlights the role of the knowledge providers and organizations in creating coordinated activities to allow the sharing of assimilating knowledge. According to Daghfous (2004), the knowledge holders' and executive's task is crucial in this phase in promoting the process of organizational learning by transferring knowledge within the organization to minimise misunderstandings.

In addition, the participants reported that, to develop high-potential local employees, Hi Tech creates forums and facilities to allow flexible assimilation and sharing of this knowledge through discussion with their peers and external experts. This accords with the views of Latukha (2018) that 'talent development also plays a major role by providing special collaboration activities among employees" (p. 448). Whelan and Carcary (2011) also posit that the effective assimilation of knowledge hinges on efficient talent development and communication.

Furthermore, these senior managers explained how their company created activities to develop their shared and assimilated information by transforming employees' way of understanding and comprehending things to find technological solutions. This kind of transformation, related to fostering their absorptive capacity, also reflects 
Murovec and Prodan's (2009) view that research and development, training of personnel, innovation collaboration and inclination to change are positively linked to the organization's absorptive capacity. Consequently, it appears that the transformation of potential employees by the gatekeepers (senior executives) was a strategic imperative. In this strategy, as returnees, the potential employees are encouraged to share their assimilated knowledge with their colleagues to be able to be reassigned globally. Thus: "They take on important responsibilities for creating knowledge, products or services for other subsidiaries in other countries." (Luo, 2016, p. 32). Hence, in the case of Hi Tech Egypt, learning how to develop potential employees through assimilation was evidently supported by the transformation phase.

\subsubsection{Fostering Cognitive Restructuring of Potential Employees through Transformation}

The transformation phase represents the amalgamation of the unfamiliar acquired external knowledge with the organization's former related knowledge. This aspect "denotes a firm's capability to develop and refine the routines that facilitate combining existing knowledge and the newly acquired and assimilated knowledge". (Zahra \& George, 2002, p. 190) This depends on the capability of the organization's talent to take in two dissimilar sets of knowledge, mixing them to arrive at new understandings that modify the way that the organization perceives itself and comprehends the competitive environment. According to Vera et al. (2011), transformation of the cognitive structures involves organizational learning at both individual and organizational level. Firms with competencies in research and development will reap the benefits of this process (Cohen \& Levinthal, 1990). George et al. (2001) recommend that patents can be considered as an indicator to determine the organisation's capability to implement or exploit knowledge. Thus, in this study we use the existence of patents to evaluate the transformation phase.

"You can find one of our customers is the MOD (Ministry of Defence) in Egypt, because we have our distinguished standard." (AZ).

"We are in the top of our competitors in 'Hi Tech' Egypt ... because of our continuous transformation, development, training ... We prepare our potential local employees ... to exhibit our standard in their behaviour... so when you enter our company you will experience a global and standardised way of dealing with you as if you are in China, USA, or any of our branches all over the world. This is the secret of our outperformance." (AZ).

“... R\&D experts come not only from our HQs in China, but also from all over the world to share their knowledge and expertise between us in different disciplines ... to update our staff ... to remain globally informed so as to be able to reflect this information and act either in local or global positions" (WE).

"We have on the job training, and also through meetings, either formally or informally, with our executives, external peers, visitor experts, to update us with the latest technological knowledge and ... install these concepts in our minds, to be able to act elsewhere in 'Hi Tech'..."(MG)

These excerpts illustrate how senior managers of Hi Tech Egypt develop their high-potential local employees by transforming their way of seeing and judging things through the transformation process they are exposed to. This involves mingling new external knowledge to be combined with their existing knowledge via training and meetings with their external R\&D experts and internal executives. In this way they develop their awareness of the latest technology and restructure their minds with new insights toward solving problems and dealing with the new demands of different generations. This puts into practice the idea that talent development includes a selection of schemes that aim to enhance the quality of knowledge and promote knowledge transformation. This can be achieved by, for instance, "formal programs (targeting middle/senior managers and technical/ professional talent categories), relationship-based developmental experiences (interaction with peers, senior leaders, customers, and suppliers), job-based developmental experiences, and informal/non-formal developmental activities" (Latukha, 2018, p. 448). This also means that anyone visiting Hi Tech will find the same ways of dealing with issues and behaving in a standardised manner, as if the employees have been trained locally to act globally: this is referred to as reverse adaptation.

The participants confirmed that, based on their global standards, they had obtained patents as a key provider with the Egyptian Ministry of Defence, which is an indicator of the transformation process and knowledge application. The executives also explained how their peer experts and executives instil into their employees their innovative ways of thinking and creativity, from the perspectives of a range of different disciplines, to foster their absorptive capacity to represent Hi Tech elsewhere. This corroborates the findings of Latukha (2018) that talent development "aims to extend employees' capabilities related to innovative thinking and creativity and their key competences" (p. 453). This should be indispensable for the formation and improvement of an organization's absorptive capacity (Gilley et al., 2008). Consequently, "Cultivating and transforming local talent to become 
global talent necessitates bringing together a multitude of efforts by organizations, units and the employees themselves" (Luo, 2016, p. 38). Thus, fostering the cognitive restructuring of potential employees through the transformation phase of the ACAP model is a crucial component for reverse adaptation. It is also evident that the transformation phase has to be at the forefront of the ACAP model, as a prerequisite for knowledge identification and assimilation. This is because the mind-set of the Hi Tech employees has to be firstly transformed in terms of cognitive structure, before the employees can assimilate and combine knowledge in a standardised way that conforms to their organization's strategy and structure. They are then fit to benefit their organization and to be reassigned elsewhere (reverse adaptation).

\subsubsection{The Role of Expatriates in Fostering Trust for Developing Local Potential Employees}

Social integration mechanisms involve a group of employees sharing relevant knowledge between the organization's members and help to avoid miscommunication in this process. Thus, "Informal mechanisms (e.g. social networks) facilitate the exchange of ideas, formal ones (e.g. the use of coordinators) are more systematic in promoting the flow of information and knowledge within the firm" (Engelman \& Schreiber, 2018, p. 8).

The creation of shared identity, the formation of trusting connections and lack of conflict among an organization's employees can be deemed as proxies of the social integration mechanism (Zahra \& George, 2002). This enables managers to enhance knowledge sharing and reconfiguration (Jansen et al., 2005).

"The headquarter sent continuously foreigner experts to meet with our staff to transfer their knowledge through formal/informal meetings ... without any kinds of disagreement." (AZ).

"In these meetings with our peers, externals, and senior managers present their ideas, research outcomes, innovative solutions, via data show devices and open discussions, so we can communicate and share our knowledge with each other." (AS).

"However, developing local talent does not mean we negate the role of externals and expats in developing our talent; they have a complementary role to our endeavours, as they help in transferring their long experience, accumulated knowledge, to our locals... They transfer openness, flexibility, self-assurance, and trust ... so that we rely on them in transforming minds of our local talent to fit in other global positions." (AY).

In these extracts, the participants reaffirm the role of expatriates in fostering trust to develop local high-potential employees in their organization. Through social integration they enable staff to "place themselves in social contexts' (Cohen 2004, pp. 678-679), thus interacting with others in their organization. Dialogue is deemed as the main component for the participation of both "sides", where they have reciprocity of knowledge with each other in a climate of openness. Through dialogue, different people are heard, which in turn can change one party's idea of the "Other", as well as rethinking the position of "Self", and affecting one's ontological security (Kinnvall \& Nesbitt-Larking, 2011, p. 94-193).

The social and informational events $\mathrm{Hi}$ Tech created and their belief in the benefit of sending indigenous and external expatriate employees to mingle and interact with their employees as host country nationals (HCNs) is consistent with the view of Wang and Varma (2018) that such interactions can bring new knowledge, practices and exposure to a global perspective for the HCNs. Consequently, this "can concurrently create complementary synergies and promote mutually beneficial supportive behaviours" (p.671).

In the same vein, this interaction between expats/ HCNs promotes trust, which in turn helps in creating and sharing knowledge and personal experience. This is also consistent with the view of other authors that individuals' relationships with their colleagues will benefit when they share their personal experiences, because these network ties constitute a social integration mechanism which contributes to establishing and increasing trust (Liu et al., 2014; Nonaka, 1994; Zahra \& George 2002).

Along with this, it has been argued that "inter-organizational" trust is an important component of absorptive capacity, since it makes the "teacher" organization keen to help the "student" subsidiary to comprehend the transferred knowledge (Lane et al. (2001).

However, transforming the mind-set of the high-potential HCNs is a prerequisite before engaging in the reciprocity of knowledge creation and transfer with the expatriates, as it is claimed that this "requires the active engagement of both parties as well as certain structural and cognitive preconditions" (Lane et al., 2001, p. 1141).

Thus, $H i$ Tech created these educational and social events as supporting activities to foster trust, develop its local high-potential employees and ensure their success. This corroborates the findings of Wang and Varma (2018) that, as "host country-expatriate interactions are critical to the success of both expatriates and HCNs, organizations should intervene and facilitate conditions that foster such interactions, which can lead to better understanding 
and appreciation of each other" (p. 670). Thus to be equipped for global reassignment, the employee's mind-set should first be transformed and supported by trust to succeed and have a better understanding of the transferred knowledge. This suggests that the transformation phase should be at the forefront of the ACAP model (Zahra \& George, 2002).

3.1.8 Fostering Learning of Local High-Potentials by Reverse Adaptation Champions via Exploitation of Knowledge

The transformation phase is defined "as an organizational capability that is based on the routines that allow firms to refine, extend, and leverage existing competencies or to create new ones by incorporating acquired and transformed knowledge into its operations" (Zahra \& George, 2002, p.190). At this stage, organizations might attempt to improve or remove knowledge in their existing knowledge repository that forms the organization's way of thinking (Zahra \& George, 2002). Through the exploitation phase organizations attempt to create new competitive advantage by exhibiting their ability to incorporate the knowledge accumulated and transferred through the other three stages for commercial ends (Zahra \& George, 2002). However, as organizations "vary in their ability to create value from their knowledge base" (Zahra \& George 2002: 191), their capability to exploit relies on developing organizational skills and capabilities to achieve competitive advantage by implementing knowledge that has been transferred and amalgamated into production and innovations.

“We exploit our transformed ideas' outcome from continuous meetings, training, coaching and socializations with our executive managers, external experts and research in new products; for instance ... the internet fiber cabins scheme in all over Alexandria the second capital of Egypt, so as to transfer very high speed internet capacity ..." (AZ).

"We are not only relying on workshops, seminars, and meetings with global experienced experts... for keeping our staff in the loop of our technology strategies, and structure, but also for selling and sharing knowledge and information regarding promoting our products, innovations, and customers' needs." (MG).

In the above extracts, senior managers emphasise that their formal and informal interaction with their external experts who have been managing globally in other $\mathrm{Hi}$ Tech subsidiaries enabled them to combine, and implement the existing knowledge and ideas accumulated through the other stages of the ACAP into new products, innovations and inventions in different parts of Egypt, according to its environmental needs. This is aligned with other views that knowledge about the environment enables individuals within organizations to improve their understanding regarding how they will integrate the existing product. "The focus is not on the product per se, but on the interactions between the product and the different environments, both within and outside the firm's boundaries" (Aribi \& Dupouet, 2016, p.104). Thus, in the exploitation phase, "coordination capabilities are visible through the intense one-to-one communications and negotiations that take place to fit the product into the existing portfolio" (ibid, p.1, 6). This highlights the role of reverse adaptation champions who acting as bees scanning the environment and pollinating Hi Tech's different parts with innovations and ideas to be implemented for commercial ends and gain competitive advantages.

3.1.9 Openness, Self-Enhancement, and Cultural Intelligence as Global Mind-Set Competencies and Criteria for Hiring in Hi Tech Egypt

Levy et al. (2007) have described openness as the mind-set of global leaders and the articulation of different 'business realities' at the local and global levels. It has been argued that to develop local talent, many MNEs try to adopt 'Western' criteria by revising human resource management practices, for instance, through performance assessments and crystal-clear promotion prospects (Meyer \& Katherine, 2018). In their study, Meyer and Katherine (2018) found that, although MNEs faced a scarcity of global leaders in China, they overcame this deficiency in transferring knowledge and leadership by "recruiting and attracting Chinese potentials with a Western mind-set, and that Chinese nationals are adapting to the Western concept of leadership, not the other way around" (Schmidt et al., 2014, p. 107). This echoes the definition of reverse adaptation. The authors relate this to two emerged competencies mentioned by Ralston et al. (1996). The first competency is Openness to change, which relates to willingness to accept new ideas and ways of doing things, versus the degree to which managers desire to preserve the status quo and the certainty that it provides in relationships with others. The second competency is self-enhancement, which attaches greater attention to social power than traditional power (Ralston et al. 1996, p. 5). According to Gupta and Govindarajan (2002), a global mind-set can also be defined as "an openness to and awareness of diversity across cultures and markets with a propensity and ability to synthesize across this diversity” (p. 117).

In addition, cultural intelligence or cultural quotient (CQ), has been defined as the set of managerial skills needed to govern culturally diverse individuals, and it is deemed as the cause of innovative behaviours in 
workforces, creative practices in the workplace and the development of resilient ideas (Korzilius et al., 2017). Therefore, cultural intelligence is pertinent to business on both a global and local basis (Schlegel \& Sarstedt, 2016). It has also been confirmed that the there is a mediated relationship among the dimensions of openness, cultural intelligence, and self-awareness (Duff et al., 2012).

"We have core values and standards in recruiting and developing our employees such as openness to accept other cultures, looking forward to learning continuously, have ethical and behavioural values, striking balance among their personal, professional life, and work commitments, always seeking to develop themselves. (AS).

"We have certain criteria in selecting our employees, and training schemes according to his/ her areas of expertise. Points in their assessments are accumulated to hire who get the highest points in the cognitive, open-minded, behavioural and psychological evaluations." (AY).

"They are looking for open-minded people, with flexibility and creative ambitious individuals who can communicate with others effectively. Culture skills are one of our main criteria in the selection decision..." (WE).

"In 'Hi Tech', we select our employees not based only qualification ... but also on their mind-set capability to accept and transfer other cultures, we have also CQ levels in recruitment... These levels have to do with their physical and emotional, and cognitive congruity with cultural intelligence skills and behaviour thus we transform them." (AZ).

The data analysis revealed that openness, self-enhancement and cultural intelligence are among the main recruitment criteria that $H i$ Tech Egypt relies upon. The senior managers stated that they are looking for employees who are open to accepting and dealing with other cultures, and different backgrounds, not restricted to their own ideas and beliefs and able to tolerate misunderstandings. They also innovate, being creative and ambitious, and seeking learning, to be prepared for relocation elsewhere. These findings confirm those of other researchers, such as Ones and Viswesvaran (1997), that individuals with more openness are not restricted to their own cultural values and beliefs but are attracted to learn about unexplored ideas and innovations. Likewise, those who are open to experience are inclined to question their own cultural background, be innovative and keen to learn by accumulating information linked to cultural similarities and differences (Costa \& McCrae, 1992). Open-minded people are flexible and interested in other cultures, which inspires them to learn about other cultures' backgrounds (Ward et al., 2009). Consequently, openness and being ambitious for self-enhancement is an "essential trait for a worker who needs to interact with the diverse perspectives and work styles experienced in multicultural teams" (Duff et al., 2012, p. 5). Thus, openness and self-enhancement are key drivers for reverse adaptation in Hi Tech Egypt.

Hi Tech's Egypt senior managers accentuated the importance of CQ in their selection and recruitment criteria, since individuals with high CQ are inclined to exhibit tolerance for ambiguity and misunderstanding. They described such individuals as being able to compromise between their culture and other cultures, helping business to achieve competitive advantage, and having high levels of cognitive, psychological, and behavioural skills. This is aligned with the views of other authors, such as Daryani et al. (2017), who argue that cultural intelligence is linked to the manager's skill to adjust to principles and values dissimilar to his or her own.

The psychological component of cultural intelligence enables individuals to show that they are interested other cultures and attempt to accept and respect them (Shayanipour et al., 2017). Daher (2015, p. 170) recommends the measurement of cultural intelligence as a valuation instrument for recruiting, training, and selection criteria, since an individual with high cultural intelligence can extrapolate those cultural features that would be true in all groups of individuals.

Consequently, Daher (2015) argues that leaders need to have supplementary abilities, such as tolerance of ambiguity and misunderstandings, cultural empathy and knowledge of others' cultural restrictions. Thus, according to Luo (2016), a prerequisite of reverse adaptation is that, culturally, MNEs must learn to become a part of a subtle, complex system that combines respect for others, open-mindedness and motivation. By considering cultural intelligence as the "knowledge one possesses regarding cultural differences, it is expected that openness will provide for greater receptivity to new cultures" (Duff et al., 2012, p. 6). Thus, it is apparent and also empirically established that, as the main criteria for hiring and recruiting, openness, cultural intelligence and self-awareness underpin the process of reverse adaptation in Hi Tech Egypt.

\subsubsection{Transformation through Training, and Acculturation for Reverse Adaptation}

MNEs which are concerned with learning apply cross-cultural training programs for their managers, while external training agencies and consulting organizations undertake research into cross-cultural training to evaluate its success for providing enhanced information to businesses (Wurtz, 2014). Cross-cultural training improves the 
executive's efficiency and performance in the host country (Bhawuk \& Brislin, 2000). Acculturation-related education or training is important for those MNEs which seek reverse adaptation (Luo 2016, p. 37). Acculturation may be defined as "the change in cultural patterns that occurs when groups of individuals from different cultures come into continuous first-hand contact" (Redfield et al., 1936, p. 149).

Acculturation comprises three related components: "understanding the other culture's cultural values, knowing how to adjust to the other culture (e.g. adopting non-evaluative attitudes toward the culture) and understanding factors related to job performance within the other culture (e.g. learning how the culture influences attitudes toward work and formal personal interaction)" (Luo, 2016, p. 37). As such, there is an interrelated link between acculturation, and transformation that, through training, would lead to reverse adaptation.

"We provide them with training courses, we qualify them, we certify them based on the most results of research so as to update and renovate their old knowledge to fit with our strategies, not just standard training like others does, we have our systematic and strategic training." (AZ).

"In 'Hi Tech', we provide our people with Chinese language courses, multilingual courses, seminars, forums to socialise with our Chinese colleagues so as to practice their way of communication, attitudes, and ways of eating, drinking, and their implicit language, as well in order to be able to fit with their culture and way of thinking." (WE).

"Once we recruit employees, we do culture orientation periods so as to fit with our strategies, structures, and ways of doing things, then we provide them with our BCG "Business Conduct Guidelines"; as the code of ethics... We provide our employees with soft skills courses... we are very sensitive regarding dealing with other cultures, ethnicities in order to create mutual trust ... without such culture skills, trust will diminish and in turn knowledge transfer level will be sparse." (AY).

"We have also interactive training courses for those who are in continuous contacts with our Chinese and external alliances, like etiquette ... language sessions, we also are contracting with external agencies and experts to teach our staff the soft skills, management skills global skills, and communication skills." (MG).

The extracts illustrate how the transformation steps were achieved through training by socialising with Chinese colleagues, and being provided with soft skills, English courses, and behaviour courses. They were also provided with a code of ethics, so as to fit with the culture in further reallocations elsewhere in Hi Tech. Thus, "It is important to understand what determines or shapes effective cross-cultural leaders before MNEs deploy methods or trainings to cultivate their global leaders." (Ko, 2015, p. 1) which is related to transformation of mind-set before even initiating the process of learning and training. The findings of this research support the recommendations of previous researchers (Brewster, 1988, Mendenhall \& Oddou 1985) that MNEs should prepare their workforces through cultural and language training and as well as orientation sessions, to acquaint them with daily affairs. The participants' reports confirmed the conclusions of previous studies. For example, cultural orientation and cross-cultural training were among the six main categories proposed by Tung (1982) to acquaint the individual with the cultural institutions and value schemes of the host country. These categories also included concepts, attitudes, role perceptions, language training, and sensitivity training to develop attitudinal flexibility for better understanding of other cultural settings (Shen, 2005, p. 660).

These programmes also related to the concept of acculturation, where high-potential employees attended formal and informal sessions to extend their awareness of how to deal with other cultures. Thus, in order to learn how local employees adapt to global culture, such employees "should be trained and cultivated not only for technical competence" (Luo, 2016, p. 37). Consequently, acculturation is regarded as an irretrievable one-directional process enabling individuals to reverse their national culture so as to adjust the prevailing culture (Trimble, 2003). Therefore, it can be said that transforming high-potential employees through training and acculturation has contributed to reverse adaptation in Hi Tech Egypt.

3.1.11 The Role of HRD, Investment and Retention in Pooling and Transforming Local High-Potential Employees and Students

In a competitive environment, human resource development has a key role in encouraging and developing the process of creating a learning environment to generate and foster knowledge (Packard, 2017). High-potential workforces constitute a talent pool from which important positions can be filled, and talent management is the development (HRD) of the talent pool to supply these key strategic positions (Collings and Mellahi, 2009). Thus, based on the belief that efficient management of talented employees requires firms to apply qualitatively dissimilar practices than those currently used in human resource management, Talent Management has become a currently debated issue in the field of human resource management theory and practice (McDonnell et al., 2017). 
Investing in and improving talented employees' skills and competences and planning for their future intensifies their loyalty and improves retention; it is also of great benefit to the organization's competitive advantage (Lawler, 2017). Consequently, "MNEs and powerful local rivals are increasingly vying for the same global talent, propelling MNEs to build their global talent pool by cultivating local talent" (Luo, 2016, p. 33).

"Selecting talented locals does not only stop to those from other countries, but, also for Chinese themselves ... We do have difficulties in terms of funding them with temporary salaries, expenses, etc. until they fit for purpose and get recruited. But 'Hi Tech' believes that investing in their talent will pay off and outweigh" (AZ).

Thus, it can be observed that the participants emphasised the role of human resource development in fostering the selected local high-potential employees to achieve reverse adaptation through the transformation process by learning via intensive endeavours. This concurs with Luo's (2016, p. 31) belief that: "To foster local talent to become global talent MNEs must put forth tremendous effort in selecting, nurturing, coaching, training and upgrading local employees' attitudes, values, cultural fit, language skills and professional knowledge, preparing these employees to be ready for global reassignments." The senior managers also confirmed that there is no harm in investing in talented employees, as this will benefit the entire organization, which is in line with the view of Lawler (2017). Likewise, the interviewees emphasised the fact that international reassignment is not the ultimate end, but rather, continuous management development is required to progress during their career, strengthening their worldwide know-how, and exploiting their 'glocalized' capability. This supports Luo's (2016) emphasis on the role of continuous management development in underpinning the virtuous circle of reverse adaptation.

"In 'Hi Tech' we select our employees not based only qualification ... but also on their mind-set capability to accept and transfer other cultures, for instance, we do competition in the Egyptian Universities to choose the best talent individuals, we train them with temporary salaries for three month, we send them to China, we qualify them to accept our strategies and policies" (WE).

"Because talent people are rare ... we do competitions among the ... Egyptian Universities ... to select the most intelligent students, opened to accept changes and other cultures ... The first 7 will be dispatched to China, to absorb our culture, strategies, way of thinking, ... and $30 \ldots$ will be provided with summer courses, so as to return to join our team and transfer what they learned to them at any centres of our company all over the world. ... Thus we are not spending; rather we invest in our prospective pioneers." (AZ).

In the above excerpts, the senior managers emphasise the role of HRD in investing in talent and affording the required resources for the development of such individual's careers and preparing them to adopt $H i$ Tech's strategy and culture to be able to deploy them elsewhere in the world. This was due to the scarcity of talent and the voracity of competition in hunting for talented individuals among rivals and is an example of reverse adaptation. This confirms previous findings: for example, Lin et al. (2018) noted that Hi Tech relocated their "European Research Center (ERC) to Munich, Germany, which is adjacent to the Technical University of Munich, ... Hi Tech also spared no effort to attract international talent" p. 86). In addition, "Hi Tech invests in its high potential people by providing them with the right to use to Hi Tech-wide resources; Hi Tech University was formally registered for talent training and cadre selection, and human resources development" (Dong Lu et al., 2018 pp. 14-17). Moreover, qualifications were not considered as a key criterion in selecting high-potential people, because $\mathrm{Hi}$ Tech offer training and certify their own high-potentials. This also concurs with the view that, in reverse adaptation, the values, attitudes and traits of high potentials are more desirable than formal qualifications, which "are not always the best predictors of performance and retention, and that skills are easier to develop than are personality traits, attitudes and values" (Luo, 2016, p. 32).

"We have policies and schemes for retention to our employees .... Thus, we evaluate and accordingly motivate and retain our staff based on their continuous input and achievements, how they scan the environment for the best solutions to our customers, suppliers, and alliance, benefit their colleagues, come up with new, and innovative ideas. ... we send them to our $H Q$ s and other parts in the world to rotate them to get profound experience." (MG).

In this excerpt, a senior manager explains how their retention scheme is tailored to the high-potential individual's input, performance and achievements. Hi Tech evaluates its talent individually. This is consistent with other findings. For instance, Dong Lu (2018) concluded that Hi Tech offers a global growth platform that gives the workforce the chance to shoulder greater responsibilities and accelerate their careers, along with contribution-based performance assessments and promotions that stimulate the commitment of its teams. This incentive mechanism creates market-facing employees who always feel the need for innovation to sustain growth under competition, because Hi Tech has often said: "We are not hiring staff, but partners" (ibid., pp. 9-12). Consequently, it appears that the transformation of high potential employees and students has to be supported by 
continuous management development, in terms of HRD activities, in pooling for high-potential students among the universities, funding and investing in high-potential employees, and preparing retention schemes that evaluate teams and potentials according to their achievement. This approach is due to vigorous competition among MNEs and influential local competitors for the same global talent, driving multinational organizations to construct their worldwide talent pool by cultivating their local talent (Luo, 2016).

\section{Conclusion}

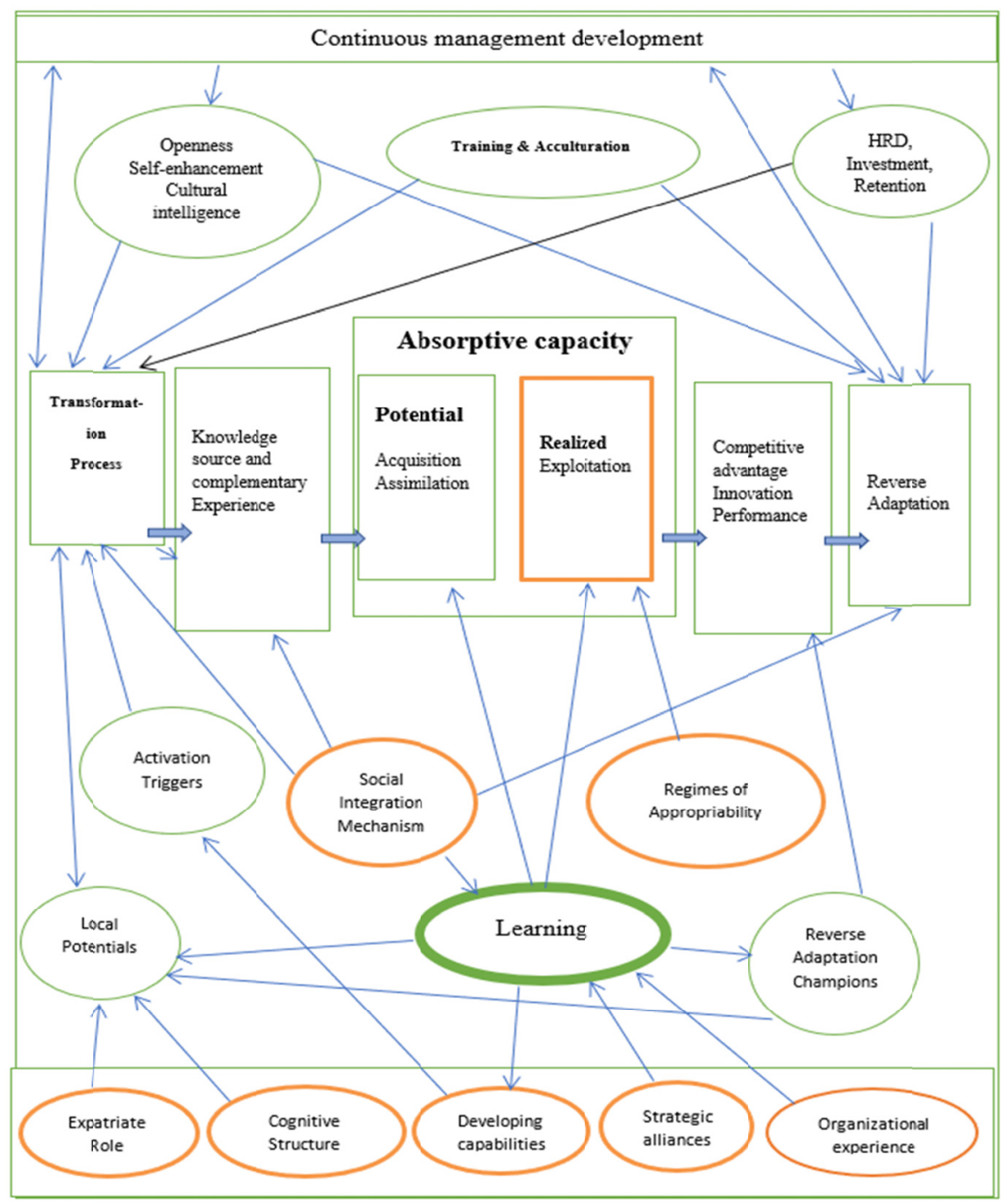

Figure 2. Enablers of reverse adaptation

The findings of this study emphasise that, due to the competitive market for talented individuals, MNEs need to foster local talent to fill the skills gap and allow them to reassigned talent elsewhere in their globalized subsidiaries. To do this, they must enable these talented individuals to adapt their structure, strategy, and way of thinking. It is suggested that these types of activities, known as reverse adaptation, enable MNEs to generate competitive advantage. In addition, cultivating and transforming local talent to become global talent requires the individual's mind-set to be transformed, enabling them to absorb external and internal knowledge and operationalize both into beneficial outcomes. This requires efforts from all levels in MNEs, including subsidiary and individual levels, in their cultural, professional, structural, informational and executive practices. This research uses absorptive capacity as a theoretical lens, "because it allows firms to enhance their ability to comprehend, connect, combine, identify and apply environmental knowledge" (Albort-Morant et al., 2018, p. 2) to investigate the way that MNE's local employees learn, assimilate and modify their personal behaviour and professional competence in order to fit the MNE's global mind-set and global competence set to allow 
international reassignment.

To address previous calls for research, this study attempted to determine which phase is dominant in the Absorptive Capacity (ACAP) processes, and thus how to foster, cultivate and enforce that phase to enable reverse adaptation to succeed. Finally, MNEs may only be able to accomplish their aspired strategic goals if they can transform, develop, attract, motivate, and retain their high-potential employees to implement strategies that can be implemented elsewhere in the organization. In this regard, we offer Figure 2.

As shown in Figure 2, by using absorptive capacity as a framework, the research indicates that organizational, team, and individual previous experience are deemed as enablers of learning that foster transformation to achieve reverse adaptation. It also indicates how learning by doing can harness employees' absorptive capacity, which helps them to be globally reassigned. In addition, learning through strategic alliances for talent development can foster transformation, as an initial phase in the ACAP model suggested by Zahra and George (2002). Our findings indicate that the individual's mind-set and way of thinking need to be transformed to absorb external knowledge from the alliance so as to achieve the required learning for reverse adaptation. The participants indicated that employees learn by developing capabilities for satisfying triggers for reverse adaptation through searching for information to satisfy the needs of customers. Thus, they have to be first transformed and appropriately prepared with competencies, values and skills, before responding to organizational triggers for different contexts and generations. Thus, the employee's transformation phase appears not to mediate the process of the ACAP model: rather it precedes the four stages of the model. It subsequently has to be fostered and nurtured to transform the employee's competencies, attitudes, and skills to be able to globally be reassigned from their present location. Moreover, the investigation of the Hi Tech case highlighted that the transformation of local potential through knowledge acquisition for reverse adaptation does not end in achieving competitive advantage. Rather, reverse adaptation is a complementary stage and a by-product of the ACAP model, acting as a trigger for knowledge acquisition. Furthermore, $\mathrm{Hi}$ Tech created activities to develop their high-potential employees by sharing the assimilated information through transforming their way of understanding and comprehending things to find technological solutions. Thus, learning how to develop potential employees through assimilation is supported by the transformation phase.

What is more, for these Hi Tech managers, achieving the cognitive restructuring of potential employees through the transformation phase of the ACAP model is a crucial component for reverse adaptation. As such, the transformation phase has to be a prerequisite for knowledge identification. The role of expatriates in fostering trust for developing local potential employees, as shown in Figure 2, emphasises the importance of expatriate interactions in enabling the success of both expatriates and home country nationals. Firms should therefore facilitate situations that foster such interactions, which can lead to better understanding and appreciation of each other's cultures, thus mediating and underpinning the structure between transformation and reverse adaptation. Figure 2 shows that the learning of local high-potentials is assisted by reverse adaptation champions, who act as "bees" scanning the environment and "pollinating" Hi Tech's different parts with innovations and ideas to be implemented into commercial ends. Openness, self-enhancement and cultural intelligence, as global mind-set competencies, constitute indispensable criteria for hiring in Hi Tech Egypt. They seek open-minded, creative and ambitious people who can accept and deal with different cultures and backgrounds without being restricted to their own ideas, who seek learning and are prepared for relocation elsewhere. It also indicates the role of continuous management development in underpinning the process of transformation for reverse adaptation in $H i$ Tech Egypt. The use of transformation through training and adoption of the concept of Acculturation for Reverse Adaptation confirms that MNEs have to first determine how to reshape their high-potential employees' mind-set via cross-cultural competencies. Once this is achieved they can set up techniques or make preparations to cultivate those global leaders for reverse adaptation.

In conclusion, our paper has presented empirical evidence that the transformation stage in the absorptive capacity model by Zahra and George (2002) has to be placed in the forefront of the model. In the case of Hi Tech Egypt, it was found that the potential employee's mind-set has to be transformed, reshaped, and cognitively restructured before identifying external knowledge from beyond the boundaries of the organization. This refutes the linearity of the Zahra and George ACAP model, as it clearly demonstrates that the transformation stage does not mediate the process of the model: rather, it has to precede the other steps of the model.

In answer to the question "Is a firm's realized absorptive capacity a mediating variable in the PACAP?" (Albort-Morant et al., 2018, p. 3), the findings of this study indicate that the realised capacity is included in the transformation stage. This outcome extends our understanding of the non-linear linkages among the two subdivisions of the Zahra and George ACAP model and its phases. In addition, the current research reveals the interrelated components that lead to reverse adaptation and how continuous management developments are 
intermediated by learning that support the process of transformation for reverse adaptation. Finally it was found that the ACAP does not end in achieving competitive advantage; rather, reverse adaptation is the complementary stage and a by-product of the ACAP model, as it constitutes a trigger for knowledge acquisition. The findings also demonstrate the well-bound reciprocity of the relationship amid continuous management developments, transformation, and reverse adaptation as a virtuous cycle, and an integrated adaptation learning loop. Likewise, the current research has answered the question asked by Luo (2016) regarding how "MNE's local employees learn, assimilate and modify their personal behaviour (e.g. values, norms) and professional competence (e.g. standards, goals, language, knowledge, capabilities) in order to fit the MNE's global mind-set and global competence set so that they can be internationally reassigned" (p. 29), by proposing the theoretical framework presented in Figure 2 above.

\subsection{Limitations and Recommendations for Future Research}

As the current research is qualitative, its limitation is in its idiosyncrasy and description of only one organization. Moreover, the data gathered represents only a small sample of the employees of the organization studied, $\mathrm{Hi}$ Tech Egypt. Therefore, future researchers should be aware of this contextual limitation in using this research as a base or guide.

The current study was conducted with senior managers and did not collect evidence from other categories of employees in the same organization. Further research should be conducted with frontline managers, CEOs or a hybrid between managers and their expatriate colleagues, for their insights. Moreover, further research may consider the moderating effects that influence the knowledge transfer between host country national employees and their expatriate colleagues in the same organization, such as ethnicities, gender, and generational differences, that might hinder knowledge transfer depending on the degree of ontological security. Furthermore, future research needs to investigate how the organizational structure and the culture of eastern MNEs impact the process of transforming, cultivating, developing, motivating, and attracting local talent for reverse adaptation to become globally competent, with some distinctive methods that are dissimilar to western approaches.

\section{References}

Albort-Morant, G., Henseler, J., Cepeda-Carrión, G., \& Leal-Rodríguez, A. L. (2018). Potential and realized absorptive capacity as complementary drivers of green product and process innovation performance. Sustainability, 10(2), 381.

Ali, M., Ali, I., Al-Maimani, K. A., \& Park, K. (2018). The effect of organizational structure on absorptive capacity in single and dual learning modes. Journal of Innovation \& Knowledge, 3(3), 108-114.

Aljanabi, A. R. A., \& Kumar, M. (2013). Talent management strategy and absorptive capacity as antecedences of an innovation capability: A conceptual framework. Research Journal of Social Science \& Management, 2(9), $115-123$.

Argote, L. (2013). Organizational learning: Creating, Retaining and Transferring Knowledge (2nd ed.). New York: Springer.

Argote, L., \& Miron-Spektor, E. (2011). Organizational Learning: From Experience to Knowledge. Organization Science, 22.

Aribi, A., \& Dupouet, O. (2016). The role of knowledge processing systems in firms' absorptive capacity. Journal of Innovation Economics \& Management, (1), 87-111.

Bhanugopan, R., \& Fish, A. (2007) Replacing expatriates with local managers: An exploratory investigation into obstacles to localization in a developing country. Human Resource Development International, 10, 365-381

Bhawuk, D. P., \& Brislin, R. W. (2000). Cross-cultural training: A review. Delhi Business Review, 49(1), $162-300$

Bird, A., \& Mendenhall, M. E. (2015). From cross-cultural management to global leadership: Evolution and adaptation. Journal of World Business 51(1), 115-126. https://doi.org/10.1016/j.jwb.2015.10.005

Braun, V., \& Clarke, V. (2006). Using Thematic Analysis in Psychology. Qualitative Research in Psychology, 3, 77-101.

Brewster, C. (1988). The Management of Expatriates Human Resource Research Centre Monograph 2. Cranfield Institute of Technology, Cranfield.

Caligiuri, P. M. (2006). Developing Global Leaders. Human Resources Management Review, 16(2), 219-228.

Causin, F. G, \& Ayoun, B. (2011). Packing for the trip: A model of competencies for successful expatriate 
hospitality assignment. International Journal of Hospitality Management, 30(1), 795-802. https://doi.org/10.1016/j.ijhm.2010.12.011

Cohen, S. (2004). Social Relationships and Health. American Psychologist, 59(8), 676-684.

Cohen, W. M., \& Levinthal, D. A. (1990). Absorptive capacity: a new perspective on learning and innovation. Administrative Science Quarterly, 35(1), 128-152.

Collings, D., \& Mellahi, K. (2009). Strategic Talent Management: A Review and Research Agenda. Human Resource Management Review, 19(4), 304-313.

Collings, D. G. (2014). Toward mature talent management: Beyond shareholder value. Human Resource Development Quarterly, 25, 301-319.

Costa, P. T. Jr., \& McCrae, R. R. (1992). Normal personality assessment in clinical practice: The NEO personality inventory. Psychological Assessment, 4(1), 5-13.

Creswell, J. W., \& Poth, C. N. (2018) Qualitative Inquiry and Research Design Choosing among Five Approaches. 4th Ed. Thousand Oaks, Ca.: SAGE Publications Inc.

Daghfous, A. (2004). Absorptive capacity and the implementation of knowledge-intensive best practices. SAM Advanced Management Journal, 69(2), 21.

Daher, N. (2015). Emotional and cultural intelligences as an assessment tool for recruiting, selecting and training individual candidates. International Journal of Business \& Public Administration, 12(1), 167-180.

Daryani, S. M., Aali, S., Amini, A. \& Shareghi, B. (2017). A comparative study of the impact of emotional, cultural, and ethical intelligence of managers on improving bank performance. International Journal of Organizational Leadership, 6(2), 197-210.

Duff, A. J., Tahbaz, A., \& Chan, C. (2012). The interactive effect of cultural intelligence and openness on task performance. Research and Practice in Human Resource Management, 20(1), 1-12.

Engelman, R., \& Schreiber, D. (2018). ACAP Model and Innovation in UI Relationship. Contemporary Journal of Economics and Management, 16(2), 29-52.

Englander, M. (2012). The interview: Data collection in descriptive phenomenological human scientific research. Journal of Phenomenological Psychology, 43(1), 13-35. https://doi.org/10.1163/156915212X632943

Flatten, T. C., Engelen, A., Zahra, S. A., \& Brettel, M. (2011). A measure of absorptive capacity: Scale development and validation. European Management Journal, 29, 98-116.

George, G., Zahra, S. A., Wheatley, K. K., \& Khan, R. (2001). The effects of alliance portfolio characteristics and absorptive capacity on performance: a study of biotechnology firms. The Journal of High Technology Management Research, 12(2), 205-226.

Gilley, A., Dixon, P., \& Gilley, J. W. (2008). Characteristics of leadership effectiveness: Implementing change and driving innovation in organizations. Human Resource Development Quarterly, 19, 153-169.

Govindarajan, V., \& Ramamurti, R. (2011). Reverse innovation, emerging markets and global strategy. Global Strategy Journal, 1(3), 191-205.

Gupta, A. K., \& Govindarajan, V. (2002). Cultivating a global mindset. Academy of Management Executives, $16(1), 116-126$

Hansen, M.T (2002) Knowledge Networks: Explaining Effective Knowledge Sharing in Multiunit Companies. Organization Science, 13(3), 232-248.

Hart, T. A., Gilstrap, J. B., \& Bolino, M. C. (2016). Organizational citizenship behavior and the enhancement of absorptive capacity. Journal of Business Research, 69(10), 3981-3988.

Jansen, J. J., Van Den Bosch, F. A., \& Volberda, H. W. (2005). Managing potential and realized absorptive capacity: How do organizational antecedents matter? Academy of Management Journal, 48, 999-1015.

Jones, O. (2006). Developing absorptive capacity in mature organizations: The change agent's role. Management Learning, 37(1), 355-376.

Kim, L. (1997). Imitation to innovation: The dynamics of Korea's technological learning. Harvard: Harvard Business Press.

Kinnvall, C., \& Nesbitt-Larking, P. (2011). The Political Psychology of Globalization: Muslims in the West. Oxford: Oxford University Press. 
Ko, H. C. (2015). Cross-cultural leadership effectiveness: Perspectives from non-western leaders. Management and Organizational Studies, 2(4), 1-15.

Korzilius, H., Bücker, J. L. E., \& Beerlage, S. (2017). Multiculturalism and innovative work behavior: The mediating role of cultural intelligence. International Journal of Intercultural Relations, 56, 13-24.

Kumar, N. (1995). Intellectual property protection, market orientation and location of overseas R\&D activities by multinational enterprises. World Development, 24(4), 673-688.

Lane P.J., \& Lubatkin, M. (1998). Relative absorptive capacity and inter-organizational learning. Strategic Management Journal, 19(8), 461-477.

Lane, P. J., Salk, J. E. \& Lyles, M. A. (2001). Absorptive capacity, learning, and performance in international joint ventures. Strategic Management Journal, 22(12), 1139-1161.

Latukha, M. O. (2018). Talent development and its role in shaping absorptive capacity in emerging market firms: The case of Russia. Advances in Developing Human Resources, 20(4), 444-459.

Lawler, E. (2017). Reinventing Talent Management: Principles and Practices for the New World of Work (1st ed.). Oakland, Ca: Berrett-Koehler Publishers Inc.

Levitt, B., \& March, J. G. (1988). Organizational learning. Annual Review of Sociology, 14, 319-340.

Levy, O., Beechler, S., Taylor, S. \& Boyacigiller, N.A. (2007). What we talk about when we talk about 'global mindset': Managerial cognition in multinational corporations. Journal of International Business Studies, 38, 231-258.

Lim, J., Dai, G., \& Meuse, K. (2009). Managing Global Enterprises: The Critical Developmental Needs of Chinese Executives. Retrieved from http://www.kornferryinstitute.com/files/pdf1/Chinese Ldrshp1.pdf

Lin, X., Liu, B., Han, J., \& Chen, X., (2018). Industrial upgrading based on global innovation chains: A case study of Huawei Technologies Co., Ltd. Shenzhen. International Journal of Innovation Studies, 2(3), 81-90.

Liu, H., Chen, Z., Ke, W., \& Chen, X. (2014). The impact of enterprise social networking use on team performance: Transactive Memory System as an explanation mechanism. Proceedings - Pacific Asia Conference on Information Systems, PACIS 2014.

Liu, L. A., Adair, W. L., Tjosvold, D., \& Poliakova, E. (2018). Understanding intercultural dynamics: Insights from competition and cooperation in complex contexts. Cross Cultural \& Strategic Management, 25(1), 2-31.

McDonnell, A., Collings, D., Mellahi, K., \& Schuler, R. (2017). Talent management: a systematic review and future prospects. European Journal of International Management, 11(1), 86-128.

Mendenhall, M. E., \& Oddou, G. (1985). The dimensions of expatriate acculturation: a review. Academy of Management Review, 10(1), 39-47.

Meyer, K. E., \& Xin, K. R. (2018). Managing talent in emerging economy multinationals: Integrating strategic management and human resource management. The International Journal of Human Resource Management, 29(11), 1827-1855.

Minbaeva, D., Pedersen, T., Bjorkman, I., \& Fey, C. (2014). A retrospective on: MNC knowledge transfer, subsidiary absorptive capacity, and HRM. Journal of International Business Studies, 45, 52-62.

Murovec, N., \& Prodan, I. (2009). Absorptive capacity, its determinants, and influence on innovation output: Cross-cultural validation of the structural model. Technovation, 29(12), 859-872.

Nonaka I. (1994). A dynamic theory of organizational knowledge creation. Organization Science, 5(1), 14-37.

Packard, C. (2017). Next steps: Valuing, supporting, and promoting the intersection of HRD theory and practice. Advances in Developing Human Resources, 19, 262-278.

Pegram, J., Falcone, G., \& Kolios, A., (2018). A review of job role localization in the oil and gas industry. Energies, 11(10), 2779.

Ralston, D. A., Kai-Cheng, Y., Wang, X., Terpstra, R. H., \& Wei, H. (1996). The Cosmopolitan Chinese Manager: Findings of a Study on Managerial Values across the Six Regions of China. Journal of International Management, 2, 79-109.

Reagans, R., Argote, L., \& Brooks, D. (2005). Individual experience and experience working together: Predicting learning rates from knowing who knows what and knowing how to work together. Management 
Science, 51(6), 869-881.

Redfield, R., Linton, R., \& Herskovits, M. J. (1936). Memorandum for the study of acculturation. American Anthropologist, 38(1), 149-152.

Santoso, J., \& Loosemore, M. (2013). Expatriate management in Australian multinational enterprises. $\begin{array}{lllll}\text { Construction Management } & \text { Economics, } & 13(11), & 1098-1109 .\end{array}$ https://doi.org/10.1080/01446193.2013.853129

Schlegel, C., \& Sarstedt, M. (2016). Assessing the measurement invariance of the four-dimensional cultural intelligence scale across countries: A composite model approach. European Management Journal, 34(6), 633-649.

Schmidt, C., Mansson, S., \& Dolles, H., (2014). The new face of talent management in multinational corporations: responding to the challenges of searching and developing talent in emerging economies. In Alvstam C. G., Dolles H., Ström P. (Eds.), Asian Inward and Outward FDI (pp. 87-114). London: Palgrave Macmillan.

Shayanipour, Z., Imani, M. N., \& Karimzadeh, S. (2017). An Appropriate Model for Talent Management Based on Emotional, Organizational and Cultural Intelligence. Iranian Journal of Educational Sociology, 1(5), 66-77.

Shen, J., (2005). International training and management development: theory and reality. Journal of Management Development, 24(7), 656-666.

Sjödin, D. R., \& Frishammar, J. (2015). The role of individuals for absorptive capacity in industrial R\&D. Paper presented at the IAMOT (International Association for Management of Technology) 2015 Conference, Pretoria, SA.

Todorova, G., \& Durisin, B. (2007). Absorptive Capacity: Valuing a reconceptualization. The Academy of Management Review, 32(3), 774-786. https://doi.org/10.5465/AMR.2007.25275513

Trimble, J. E. (2003). Introduction: Social change and acculturation. In Chun, K. M., Organista, P. B., Marin G. (Eds.), Acculturation: Advances in theory, measurement, and applied research. Washington, D. C.: American Psychological Association.

Tung, R.L. (1982). Selection and training procedures of US, European and Japanese multinationals. California Management Review, 25(1), 57-71.

Vera, D., Crossan, M., \& Apaydin, M. (2011). A framework for integrating organizational learning, knowledge, capabilities, and absorptive capacity. Handbook of Organizational Learning and Knowledge Management, 2, $153-180$

Wang, C. H., \& Varma, A. (2018). A process model of how interpersonal interaction leads to effectiveness of the expatriate-host country national relationship: An intergroup contact perspective. Cross Cultural \& Strategic Management, 25(4), 670-689.

Wang, C. L., \& Ahmed, P. K. (2007). Dynamic capabilities: A review and research agenda. International Journal of Management Review, 9, 31-51.

Ward, C., Fischer, R., Lam, S. F. Z., \& Hall, L. (2009). The convergent, discriminant and incremental validity of scores on a self-report measure of cultural intelligence. Educational and Psychological Measurement, 69, 85-105.

Whelan, E., \& Carcary, M. (2011). Integrating talent and knowledge management: where are the benefits? Journal of Knowledge Management, 15(4), 675-687.

Wurtz, O. (2014). An empirical investigation of the effectiveness of pre-departure and in-country cross-cultural training. The International Journal of Human Resource Management, 25(14), 2088-2101. https://doi.org/10.1080/09585192.2013.870285

Luo, Y. (2016). Toward a reverse adaptation view in cross-cultural management. Cross Cultural and Strategic Management, 23(1), 29-41.

Yao, F., \& Chang, S. (2017). Do individual employees' learning goal orientation and civic virtue matter? A micro-foundations perspective on firm absorptive capacity. Strategic Management Journal, 38, 2041-2060.

Zahra, S. A., \& George, G. (2002). Absorptive capacity: A review, reconceptualization, and extension. Academy of Management Review, 27, 185-203. 
Zhang, Y. (2012). Expatriate development for cross-cultural adjustment: Effects of cultural distance and cultural intelligence. Human Resource https://doi.org/10.1177/1534484312461637

\section{Copyrights}

Copyright for this article is retained by the author(s), with first publication rights granted to the journal.

This is an open-access article distributed under the terms and conditions of the Creative Commons Attribution license (http://creativecommons.org/licenses/by/4.0/). 